\title{
Gene Expression Analysis of the IPEC-J2 Cell Line: A Simple Model for the Inflammation-Sensitive Preterm Intestine
}

\author{
Ann Cathrine F. Støy, ${ }^{1}$ Peter M. H. Heegaard, ${ }^{1}$ Per T. Sangild, ${ }^{2}$ \\ Mette V. Østergaard, ${ }^{2}$ and Kerstin Skovgaard ${ }^{1}$ \\ ${ }^{1}$ Innate Immunology Group, National Veterinary Institute, Technical University of Denmark, Bülowsvej 27, \\ DK-1870 Frederiksberg C, Denmark \\ ${ }^{2}$ Department of Nutrition, Exercise and Sports, University of Copenhagen, Rolighedsvej 30, \\ DK-1958 Frederiksberg C, Denmark \\ Correspondence should be addressed to Ann Cathrine F. Støy; acfst@vet.dtu.dk
}

Received 31 January 2013; Accepted 20 February 2013

Academic Editors: H. Fuchs and P. Wigley

Copyright ( 2013 Ann Cathrine F. Støy et al. This is an open access article distributed under the Creative Commons Attribution License, which permits unrestricted use, distribution, and reproduction in any medium, provided the original work is properly cited.

The IPEC-J2 cell line was studied as a simple model for investigating responses of the newborn intestinal epithelium to diets. Especially, the small intestine of immature newborns is sensitive to diet-induced inflammation. We investigated gene expression of epithelial- and immune response-related genes in IPEC-J2 cells stimulated for $2 \mathrm{~h}$ with milk formula (CELL-FORM), colostrum (CELL-COLOS), or growth medium (CELL-CONTR) and in distal small intestinal tissue samples from preterm pigs fed milk formula (PIG-FORM) or colostrum (PIG-COLOS). High throughput quantitative PCR analysis of 48 genes revealed the expression of 22 genes in IPEC-J2 cells and 31 genes in intestinal samples. Principal component analysis (PCA) discriminated the gene expression profile of IPEC-J2 cells from that of intestinal samples. The expression profile of intestinal tissue was separated by PCA into 2 groups according to diet, whereas no diet-dependent grouping was seen for IPEC-J2 cells. Expression differences between PIG-FORM and PIG-COLOS were found for DEFB1, CXCL10, IL1RN, and ALPI, while IL8 was upregulated in CELL-FORM compared with CELL-CONTR. These differences, between IPEC-J2 cells and intestinal tissue from preterm pigs, both used as models for the newborn intestine, underline that caution must be exercised prior to analysis and interpretation of diet-induced effects on gene expression.

\section{Introduction}

The intestine is the site for nutrient digestion and absorption, but also a major immunological defense barrier that recognizes and responds to external antigens. In addition to the gut mucosal immune system, intestinal epithelial cells (IECs) are involved in the initiation and coordination of the intestinal immune response by the production of signaling molecules including cytokines and chemokines [1]. The IPEC-J2 cell line originates from the jejunum of an unsuckled neonatal pig [2] and is morphologically and functionally similar to IECs with microvilli and tight junctions as well as expression and production of cytokines, defensins, toll-like receptors, and mucins [2-4]. It has previously been used to investigate hostpathogen interactions and immune responses with relevance for human and swine intestinal diseases $[2,3,5-8]$ and could be a simple in vitro model to investigate the immune response of IECs in newborns.

Necrotizing enterocolitis (NEC) is a serious gastrointestinal disease in preterm infants arising from the combined effect of prematurity, abnormal bacterial colonization, and enteral feeding. In particularly, feeding with milk formula predisposes to NEC, whereas human milk is protective $[9,10]$. We set out to evaluate the IPEC-J2 cell line as an in vitro model for the preterm neonatal intestine and as a supporting model for the well-established preterm pig model of NEC, which is a valuable model for investigation of diet-induced effects [11-14]. In the preterm pig model of NEC, milk formula-fed preterm pigs have more NEC lesions compared with preterm pigs fed porcine or bovine colostrum, rich in growth- and immuno-modulatory factors $[11,15,16]$. 
Compared with animal models, cell line studies are less cost intensive, associated with no ethical concerns, and provide a highly-controlled simple model to investigate isolated factors, for example diet, on the IECs response. The IPEC$\mathrm{J} 2$ cell line has already been shown to be a valuable model for the investigation of host-pathogen interactions and could also be a promising model for in vitro studies of innate immune functions of neonatal IECs in response to dietary stimuli. In this study, we evaluated the potential of the IPEC-J2 cell line as an in vitro model to study diet-induced effects on the preterm neonatal intestine. We analyzed and compared the expression of epithelial- and immune response-related genes in the IPEC-J2 cell line and in preterm pig intestinal tissue.

\section{Materials and Methods}

2.1. IPEC-J2 Cell Line Study. IPEC-J2 cells [2] were maintained in Dulbecco's modified eagle medium (DMEM)/Ham's F-12 (1:1) supplemented with $10 \%$ fetal calf serum, penicillin $(100 \mathrm{U} / \mathrm{mL})$, streptomycin $(100 \mu \mathrm{g} / \mathrm{mL})$, pyruvate $(1 \mathrm{mM})$, and L-glutamine $(2 \mathrm{mM})$ (growth medium, Sigma-Aldrich, Brøndby, Denmark) in a humidified atmosphere of $5 \% \mathrm{CO}_{2}$ at $37^{\circ} \mathrm{C}$. Passage was performed approximately once a week, and cells between passages $82-85$ were used in the experiment. Prior to the experiment, the cell culture was found to be free of mycoplasma.

For the experiment, cells were transferred to Corning Transwell-COL collagen coated-membrane $(0.4 \mu \mathrm{m}$ pore size; Sigma-Aldrich) and grown in growth medium supplemented with epidermal growth factor $(5 \mathrm{mg} / \mathrm{mL}$; Sigma Aldrich) and insulin-transferrin-selenium $(5 \mu \mathrm{g} / \mathrm{mL}$ of each; Sigma-Aldrich) until stable transepithelial electric resistance values, measured with an EVOM-Epithelial Voltohmmeter (World Precision Instruments, Berlin, Germany), were reached after approximately $12 \mathrm{~d}$. The cells were stimulated for $2 \mathrm{~h}$ in three different diet solutions: growth medium alone (CELL-CONTR, $n=4$ ), growth medium containing $1 \%$ gamma-irradiated bovine colostrum (CELL-COLOS, $n=$ 4 ), or growth medium containing $1 \%$ milk formula (CELLFORM, $n=4)$. These conditions were selected based on results from preexperiments testing cell viability under different concentration of colostrum and periods of time. The colostrum and milk formula were identical to those used in the pig study (see later). The lipid fraction and cellular debris were removed by centrifugation at $3500 \mathrm{rpm}$ for $20 \mathrm{~min}$ at $4^{\circ} \mathrm{C}$. After stimulation, the cells were gently washed twice with Dulbecco's phosphate buffered saline (D8537, SigmaAldrich), harvested, and stored at $-80^{\circ} \mathrm{C}$.

2.2. Preterm Pig Study. Nineteen preterm pigs were delivered from four sows by Caesarean section (Large White $\times$ Danish Landrace $\times$ Duroc, Askelygaard Farm, Roskilde, Denmark) at $105-107 \mathrm{~d}$ of gestation (90\%-92\% gestation). Procedures for Caesarean section and nursing of the preterm pigs followed a standard protocol previously described in details $[11,12]$. The pigs were given total parenteral nutrition through a vascular catheter $(4 \mathrm{~mL} / \mathrm{kg} / \mathrm{h}$ advancing to $6 \mathrm{~mL} / \mathrm{kg} / \mathrm{h})$ for $2 \mathrm{~d}$ based on Nutriflex Lipid Plus (Braun, Melsungen, Germany) and adjusted in nutrient composition to meet the requirements of pigs as described by [11]. Hereafter, pigs were randomized according to birth weight into two enteral nutrition groups: gamma-irradiated $(1 \times 10 \mathrm{kGy}$, Sterigenics, Espergærde, Denmark) bovine colostrum (PIG-COLOS, $n=6$; kindly donated by Biofiber-Damino A/S, Gesten, Denmark) or milk formula (PIG-FORM, $n=13 ; 80 \mathrm{~g}$ Pepdite, $70 \mathrm{~g}$ Maxipro, and $75 \mathrm{~g}$ Liquigen per $\mathrm{L}$ of water, all products kindly donated by Nutricia, Allerød, Denmark). Bovine colostrum was collected from the first milking after parturition. The products were stored at $-20^{\circ} \mathrm{C}$ and warmed to body temperature in a water bath before feeding to the pigs (feeding dose interval: $15 \mathrm{~mL} / \mathrm{kg}$ body weight $/ 3 \mathrm{~h}$ ). Colostrum was diluted in tap water to obtain the same dry matter content as in the milk formula before use. All pigs were euthanized within the first $50 \mathrm{~h}$ after initiation of enteral nutrition according to earlier protocols [16], and tissue samples from the distal small intestinal region were immediately snap-frozen in liquid nitrogen and stored at $-80^{\circ} \mathrm{C}$. All animal protocols and procedures were approved by the Danish National Committee on Animal Experimentation.

2.3. Gene Expression Analysis. Total RNA from IPEC-J2 cells was extracted using RNeasy Mini kit (Qiagen, Ballerup, Denmark) and on-column DNAse treated using RNase-free DNase set (Qiagen) according to manufacturer's protocol. Distal intestinal tissue was homogenized, and total RNA was extracted using RNeasy Lipid Tissue Midi kit (Qiagen) and on-column DNAse treated using RNase-free DNase set (Qiagen) according to the manufacturer's protocol. Purity of extracted total RNA was assessed using UV absorption spectrums including OD 260/280 and OD 260/230 ratios on a Nanodrop ND-1000 spectrophotometer (Saveen Biotech, Aarhus, Denmark), and total RNA was quantified at OD 260. Quality (integrity) of extracted total RNA was determined using on-chip electrophoresis on an Agilent 2100 Bioanalyzer (Agilent Technologies, Nærum, Denmark). An RNA integrity number was assigned to each sample using the 2100 Expert software (Agilent Technologies, v.B.02.01).

Extracted RNA was converted into cDNA by reverse transcription of $500 \mathrm{ng}$ total RNA using the QuantiTECT Reverse Transcription kit (Qiagen), containing a mix of random primers and oligo-dT, according to the manufacturer's instructions. cDNA was diluted 1:7 in low EDTA TE-buffer (VWRBie \& Berntsen, Herlev, Denmark) prior to pre amplification. Pre amplification was performed using TaqMan PreAmp Master Mix (Applied Biosystems, Nærum, Denmark). Stocks of $200 \mathrm{nM}$ primer mix were prepared combining equal concentration of all primers used in the present study (Table 1), and in the following the genes will be denoted by their gene symbol (Table 1). TaqMan PreAmp Master Mix $(5 \mu \mathrm{L})$ was mixed with $2.5 \mu \mathrm{L} 200 \mathrm{nM}$ stock primer mix and $2.5 \mu \mathrm{L}$ diluted cDNA and incubated at $95^{\circ} \mathrm{C}$ in $10 \mathrm{~min}$ followed by 16 cycles of $95^{\circ} \mathrm{C}$ in $15 \mathrm{sec}$ and $60^{\circ} \mathrm{C}$ in $4 \mathrm{~min}$. Pre amplified cDNA was diluted at least $1: 4$ in low EDTA TE-buffer (VWR-Bie \& Berntsen) before qPCR.

Primers were designed using Primer3 (http://frodo.wi .mit.edu/) as described in [17] and synthesized at TAG 
TABLE 1: Gene symbol, forward and reverse primer sequences, and amplicon length.

\begin{tabular}{|c|c|c|c|c|c|}
\hline \multicolumn{3}{|c|}{ amplicon length. } & \\
\hline \multirow{2}{*}{$\begin{array}{l}\text { Gene } \\
\text { symbol }\end{array}$} & \multirow{2}{*}{ Sequence $\left(5^{\prime}-3^{\prime}\right)$} & & $\begin{array}{l}\text { Gene } \\
\text { symbol }\end{array}$ & Sequence $\left(5^{\prime}-3^{\prime}\right)$ & $\begin{array}{c}\text { Amplicon } \\
\text { length }\end{array}$ \\
\hline & & $\begin{array}{c}\text { Amplicon } \\
\text { length }\end{array}$ & \multirow{2}{*}{ IL6 } & F: TGGGTTCAATCAGGAGACCT & \multirow{2}{*}{116} \\
\hline \multirow{2}{*}{$A C T B$} & F: CTACGTCGCCCTGGACTTC & 76 & & R: CAGCCTCGACATTTCCCTTA & \\
\hline & R: GCAGCTCGTAGCTCTTCTCC & 10 & \multirow[b]{2}{*}{ IL8 } & F: TTGCCAGAGAAATCACAGGA & \multirow[b]{2}{*}{78} \\
\hline \multirow{2}{*}{$A L P I$} & F: TCCCAGACATACAACGTGGA & 90 & & R: TGCATGGGACACTGGAAATA & \\
\hline & R: GGTCTGGTAGTTGGCCTTGA & & \multirow{2}{*}{ IL10 } & F: CTGCCTCССАСТTTCTCTTG & \multirow{2}{*}{95} \\
\hline \multirow{2}{*}{$A O A H$} & F: GTAATGGCATTTGGGGTGTC & 97 & & R: TCAAAGGGGCTCCCTAGTTT & \\
\hline & R: TCTCCCAGCAAAATGATTCC & & \multirow{2}{*}{ IL18 } & F: CTGCTGAACCGGAAGACAAT & \multirow{2}{*}{100} \\
\hline \multirow[t]{2}{*}{ APOA1 } & F: GTTCTGGGACAACCTGGAAA & 86 & & R: TCCGATTCCAGGTCTTCATC & \\
\hline & R: GCTGCACCTTCTTCTTCACC & & \multirow{2}{*}{$I F N G$} & F: CCATTCAAAGGAGCATGGAT & \multirow{2}{*}{76} \\
\hline \multirow[t]{2}{*}{ CCL2 } & F: GCAAGTGTCCTAAAGAAGCAGTG & 103 & & R: TTCAGTTTCCCAGAGCTACCA & \\
\hline & R: TCCAGGTGGCTTATGGAGTC & & & F: ATGACAGCAAGCGAACAGTG & \\
\hline CCL3 & F: CCAGGTCTTCTCTGCACCAC & 90 & IT1H41 & R: GGGGATCCCTCTTGGTAATC & 85 \\
\hline & R: GCTACGAATTTGCGAGGAAG & & & F: AGGCCCTCACCATATCACAG & 110 \\
\hline CCL5 & F: CTCCATGGCAGCAGTCGT & 121 & 111142 & R: GTTGCCATCCAGGACTGTTT & 110 \\
\hline & R: AAGGCTTCCTCCATCCTAGC & & & F: CCCAAGGTCAATGATAAGTTGG & \\
\hline CD14 & F: GGGTTCCTGCTCAGATTCTG & 164 & $L B P$ & R: ATCTGGAGAACAGGGTCGTG & 83 \\
\hline & R: CCCACGACACATTACGGAGT & & & F: CACTCAAAGCTGTGCAGGAC & \\
\hline CD40 & F: TGAGAGCCCTGGTGGTTATC & 90 & LCT & R: GGATCCTTGGCAGAGAAGTG & 144 \\
\hline & R: GCTCCTTGGTCACCTTTCTG & & & & \\
\hline CD163 & F: CACATGTGCCAACAAAATAAGAC & 130 & MUC1 & R: ACTGTCTTGGAAGGCCAGAA & 116 \\
\hline & R: CACCACCTGAGCATCTTCAA & & & F: GCACGTCTGCAACAAGGAC & \\
\hline CD200 & & 84 & $M U C 2$ & R: CAAAGCCCTCCAGGCAGT & 125 \\
\hline & R: CCATGGTTCTTGCTGAAGGT & & & F: GAGGATGAGCTGCCCTATGAC & \\
\hline CLDN3 & F: ATCGGCAGCAGCATTATCAC & 94 & NFKBIA & R: CCATGGTCTTTTAGACACTTTCC & 85 \\
\hline & R: ACACTTTGCACTGCATCTGG & & & F: CTCGCACAAGGAGACATGAA & \\
\hline$C R P$ & F: GGTGGGAGACATTGGAGATG & 85 & NFKB1 & R: GGGTAGCCCAGTTTTTGTCA & 97 \\
\hline & R: GAAGGTCCCACCAGCATAGA & & & F: CGGTGAGAAGATTGGCTGAT & \\
\hline CXCL10 & & 141 & OCLN & R: TTTCAAAAGGCCTGGATGAC & 100 \\
\hline & R: GCTTCTCTCTGTGTTCGAGGA & & PAFA H & F: GCAAACTGGCTACTGTGTGAAG & \\
\hline C3 & F: ATCAAATCAGGCTCCGATGA & 76 & РАГАПIDI & R. GCACAGTCTGGTCATTGGAA & 113 \\
\hline & R: GGGCTTCTCTGCATTTGATG & & & & \\
\hline$D E F B 1$ & F: ACCTGTGCCAGGTCTACTAAAAA & 109 & PTGS2 & SATAGGAGAAACG & 100 \\
\hline & R: GGTGCCGATCTGTTTCATCT & & & SCAGCTCTGGGTCAAACTTC & \\
\hline DEFB4A & F: CAGGATTGAAGGGACCTGTT & 99 & RPL13A & F: ATTGTGGCCAAGCAGGTACT & 76 \\
\hline & R: CTTCACTTGGCCTGTGTGTC & & & R: AATTGCCAGAAATGTTGATGC & \\
\hline$F G G$ & F: GAATTTTGGCTGGGAAATGA & 86 & $S A A$ & F: TAAAGTGATCAGCAATGCCAAA & 96 \\
\hline 100 & R: CAGTCCTCCAGCTGCACTCT & 00 & & R: TCAACCCTTGAGTCCTCCAC & \\
\hline$H P$ & F: ACAGATGCCACAGATGACAGC & 105 & SFTPA1 & F: CATGGGTGTCCTCAGTTTCC & 86 \\
\hline & R: CGTGCGCAGTTTGTAGTAGG & & & R: CATCAAAAGCGACTGACTGC & \\
\hline HPRT1 & F: ACACTGGCAAAACAATGCAA & 71 & SLC5A1 & F: CTGCAAGAGAGTCAATGAGGAG & 99 \\
\hline & R: TGCAACCTTGACCATCTTTG & & & R: CCGGTTCCATAGGCAAACT & \\
\hline$I L 1 B$ & F: CCAAAGAGGGACATGGAGAA & 123 & $T F$ & F: CTCAACCTCAAAACTCCTGGAA & 82 \\
\hline & R: GGGCTTTTGTTCTGCTTGAG & & & R: CCGTCTCCATCAGGTGGTA & \\
\hline ILIRN & F: TGCCTGTCCTGTGTCAAGTC & 90 & TGFB1 & F: GCAAGGTCCTGGCTCTGTA & 97 \\
\hline & R: GTCCTGCTCGCTGTTCTTTC & & & R: TAGTACACGATGGGCAGTGG & \\
\hline
\end{tabular}

TABLE 1: Continued. 
TABLE 1: Continued.

\begin{tabular}{llc}
\hline $\begin{array}{l}\text { Gene } \\
\text { symbol }\end{array}$ & Sequence $\left(5^{\prime}-3^{\prime}\right)$ & $\begin{array}{c}\text { Amplicon } \\
\text { length }\end{array}$ \\
\hline TLR2 & $\begin{array}{l}\text { F: GTTTTACGGAAATTGTGAAACTG } \\
\text { R: TCCACATTACCGAGGGATTT }\end{array}$ & 136 \\
\multirow{2}{*}{ TLR4 } & F: TTTCCACAAAAGTCGGAAGG & 145 \\
& R: CAACTTCTGCAGGACGATGA & \\
TNF & F: CCCCCAGAAGGAAGAGTTTC & 92 \\
& $\begin{array}{l}\text { R: CGGGCTTATCTGAGGTTTGA } \\
\text { TNFAIP3 }\end{array}$ & $\begin{array}{l}\text { F: CCCAGCTTTCTCTCATGGAC } \\
\text { R: TTGGTTCTTCTGCCGTCTCT }\end{array}$ \\
\hline
\end{tabular}

Copenhagen (Copenhagen, Denmark). Primer sequences and amplicon length are shown in Table 1 . The 48 genes were chosen based on a previous study showing expression of the selected reference-, epithelial-, and immune-related genes in neonatal pig tissue [18]. Primer amplification efficiencies and dynamic range were acquired from standard curves constructed from dilution series of highly responding samples. Melting curves were inspected for all primer assays and agarose gel electrophoresis, and sequencing of most amplicons were performed to ensure primer specificity.

Quantitative PCR (qPCR) was performed in 48.48 Dynamic Array integrated fluidic circuits (Fluidigm Corporation, San Francisco, CA, USA), combining 48 samples with 48 primer sets for 2304 simultaneous qPCR reactions. Reaction mix was prepared using the following components for each of the 48 samples: $3 \mu \mathrm{L}$ ABI TaqMan Gene Expression Master Mix (Applied Biosystems), $0.3 \mu \mathrm{L}$ 20X DNA binding dye sample loading reagent (Fluidigm Corporation), $0.3 \mu \mathrm{L} 20 \mathrm{X}$ EvaGreen (Biotium, VWR-Bie \& Berntsen), and $0.9 \mu \mathrm{L}$ low EDTA TE buffer (VWR-Bie \& Berntsen). Reaction mix $(4.5 \mu \mathrm{L})$ was mixed with $1.5 \mu \mathrm{L}$ preamplified cDNA. Primer mix for each of the 48 primer sets was prepared using $2.3 \mu \mathrm{L} 20 \mu \mathrm{M}$ specific primer (forward and reverse), $2.5 \mu \mathrm{L}$ $2 \mathrm{X}$ assay loading reagent (Fluidigm Corporation), and $0.2 \mu \mathrm{L}$ low EDTA TE buffer (VWR-Bie \& Berntsen). Reaction mix, including cDNA $(6 \mu \mathrm{L})$ and primer mix $(5 \mu \mathrm{L})$, was dispensed and loaded into the integrated fluidic circuit of the Dynamic Array using the IFC Controller (Fluidigm Corporation). After loading, the Dynamic Array was placed in the BioMark real-time PCR instrument (Fluidigm Corporation), and the following cycle parameter was used: $2 \mathrm{~min}$ at $50^{\circ} \mathrm{C}, 10 \mathrm{~min}$ at $95^{\circ} \mathrm{C}$, followed by 35 cycles with denaturing for $15 \mathrm{~s}$ at $95^{\circ} \mathrm{C}$, and annealing/elongation for $1 \mathrm{~min}$ at $60^{\circ} \mathrm{C}$. Melting curves were generated to confirm a single-PCR product for each reaction (from $60^{\circ} \mathrm{C}$ to $95^{\circ} \mathrm{C}$, increasing $1^{\circ} \mathrm{C} / 3 \mathrm{~s}$ ). Reactions were performed in duplicates (cDNA replicates). Non-template controls were included to indicate potential problems with nonspecific amplification or sample contaminations. Quantification cycle $(\mathrm{Cq})$ was acquired using the fluidigm real-time PCR analysis software 3.0.2 (Fluidigm Corporation) and exported to GenEx5 (MultiD Analyses AB, Göteborg, Sweden).

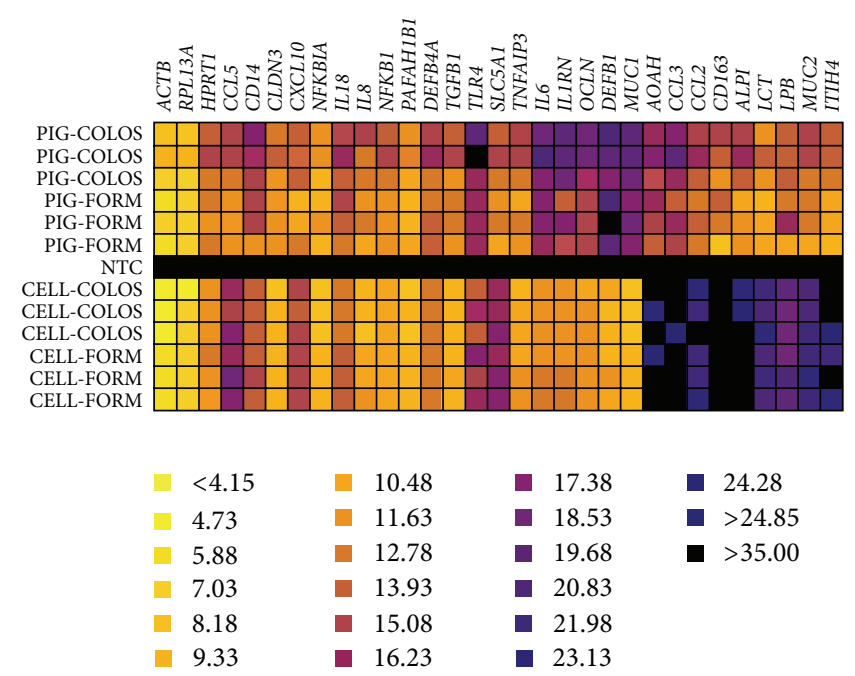

FIGURE 1: Heat map showing the $C q$ value of non-normalized raw data from representative distal small intestinal samples of preterm pigs and IPEC-J2 cells, in addition to a non-template control (NTC). A high gene expression corresponds to a low $C q$ value (yellow), while a low gene expression corresponds to a high Cq value (purple/black). Relative quantities of differentially expressed genes can be seen in Figure 2.

2.4. Data Analysis and Statistics. Data preprocessing, normalization, relative quantification, and statistics were performed using GenEx5 (MultiD Analyses AB). Data were preprocessed as follows. (1) Data were corrected for PCR efficiency for each primer assay individually. (2) Interdynamic array variation was compensated by using several highly stable samples as interdynamic array calibrators. (3) Hypoxanthine phosphoribosyltransferase 1 (HPRT1) and beta-actin $(A C T B)$ were found to be the most stably expressed reference genes in the present study using both GeNorm [19] and NormFinder [20]; therefore, the geometric mean of these two genes was used to normalize all samples in GenEx5. (4) The average of cDNA technical repeats was performed after reference gene normalization but before $C q$ was transformed to linear scale (relative quantities). In rare cases of high standard deviation between the two cDNA replicates, one or both of the samples or the primer assay were excluded from the analysis based on visual inspection of fluorescence and melting curves. To visualize differential gene expression, relative expression for all samples was calculated relative to the sample with the lowest expression for each primer set in the group of samples tested. Data were $\log _{2}$ transformed prior to $t$-test, ANOVA, and principal component analysis (PCA). Gene expression was considered significantly different if the $P$ value $<0.05$ and the relative expression $>2.0$.

\section{Results}

An overview of raw data for genes expressed in intestinal tissue from preterm pigs and in IPEC-J2 cells is presented in the heat map (Figure 1), based on color coding of the expression level before preprocessing. After preprocessing, 


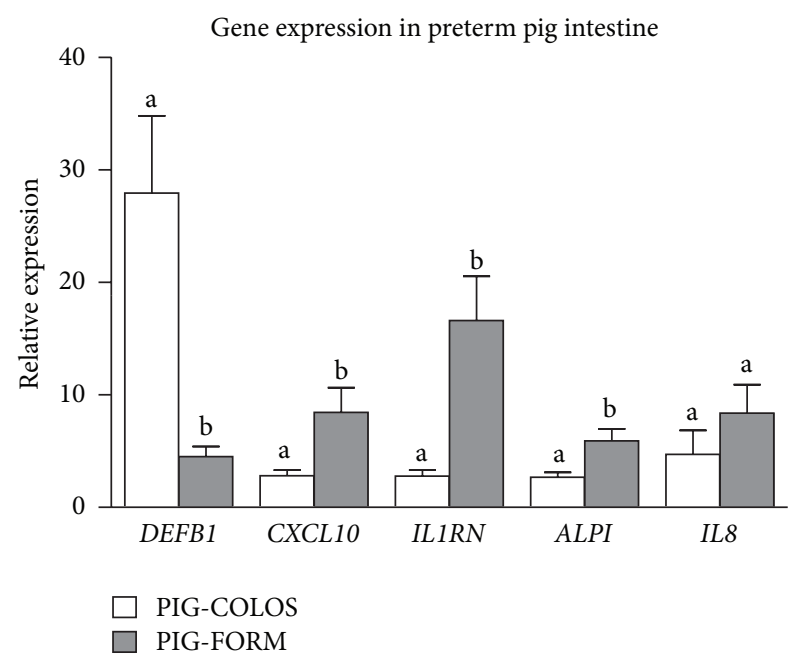

(a)

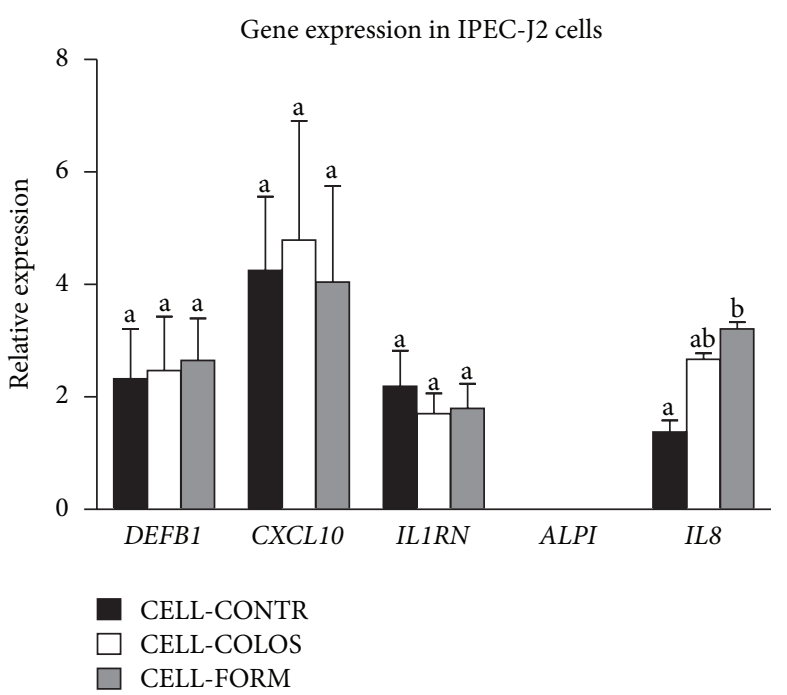

(b)

FIGURE 2: Relative expression (mean \pm SEM) of genes expressed significantly different in intestinal tissue of PIG-COLOS versus PIG-FORM (a) and between different IPEC-J2 cell treatment groups: CELL-CONTR, CELL-COLOS, and CELL-FORM (b). Relative expression for all samples was calculated relative to the sample with the lowest expression within each gene in the group of samples tested. Different superscript letters within each gene indicate significant difference $(P<0.05)$.

including visual inspection of melting curves, 31 referenceand epithelial- and immune response-related genes were expressed within the dynamic range in pig intestinal tissue, and of these, 22 genes were expressed in IPEC-J2 cells. No genes were expressed only in IPEC-J2 cells.

In PIG-COLOS, DEFB1 was more highly expressed, while CXCL10, ILIRN, and ALPI were less expressed than in PIGFORM intestinal tissue (Figure 2(a)). In IPEC-J2 cells, no differences were seen in the expression of DEFB1, CXCL10, and ILIRN between the three groups, and ALPI was not expressed in IPEC-J2 cells. In contrast, IL8 expression was significantly higher in CELL-FORM compared with CELLCONTR with intermediate expression in CELL-COLOS (Figure 2(b)). When comparing CELL-FORM and CELLCOLOS with PIG-FORM and PIG-COLOS in a PCA, two major groups were identified (Figure 3), discriminating gene expression profiles of pig intestinal tissue from that of IPECJ2 cells. Furthermore, discrimination between PIG-COLOS and PIG-FORM was achieved by PCA, while no discrimination between CELL-COLOS and CELL-FORM was observed. As expected, major differences in gene expression were seen between IPEC-J2 cells and pig intestinal tissue, which accounted for the clear clustering in the PCA.

Transcript coding for CXCL10, CCL5, and SLC5A1 was found at a higher level in pig intestinal tissue compared with IPEC-J2 cells; in contrast, the expression of CLDN3, DEFB1, ILIRN, IL6, MUC1, and OCLN was lower in intestinal tissue compared with IPEC-J2 cells (data not shown).

\section{Discussion}

In this study, the IPEC-J2 cell line was evaluated as a possible in vitro model for investigation of the gene expression of

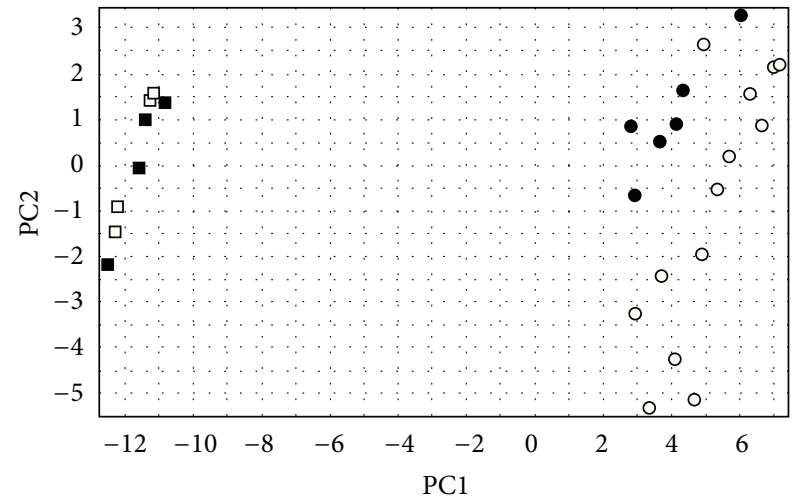

Figure 3: Principal component analysis of expression data from distal small intestinal tissue from preterm pigs: PIG-FORM (white circles) and PIG-COLOS (black circles) and IPEC-J2 cells: CELLFORM (white squares) and CELL-COLOS (black squares).

IECs in relation to dietary effects on the neonatal intestine. To our knowledge, this is the first demonstration of CCL5, CD14, CXCL10, IL1RN, PAFAH1B1, and SLC5A1 expression in IPEC-J2 cells. The expression of DEFB1, DEFB4A, IL6, IL8, IL18, MUC1, NFKBIA, NFKB1, OCLN, TLR4, TGFB1, and TNFAIP 3 has been reported previously $[2-6,21]$. On the other hand, a lack of TGFB1 expression has also been reported in infection studies [2]. Finally, we confirmed the lack of expression of CCL2 [4] and MUC2 [2] in IPEC-J2 cells.

We found that the IPEC-J2 cells and intestinal tissue clustered in two distinct groups in the PCA of gene expression patterns. Furthermore, it was possible by PCA to discriminate between the gene expression profiles of intestinal tissue from 
preterm pigs in different diet groups; however, discrimination by PCA between the IPEC-J2 cell diet groups, CELLFORM and CELL-COLOS, was not possible. Four genes were differentially expressed between pigs fed milk formula or colostrum. DEFB1, encoding the antimicrobial protein defensin betal [22], was upregulated in PIG-COLOS compared with PIG-FORM, which suggests that colostrum may stimulate the host antimicrobial response. The expression of $A L P I$, coding for the enzyme intestinal alkaline phosphatase, in addition to CXCL10 and ILIRN was downregulated in PIG-COLOS compared with PIG-FORM. CXCL10 is involved in T-lymphocyte activation and induction of chemotaxis toward infected tissues [23]; and ILIRN, coding for the IL1 receptor antagonist, has previously been found to show similar expression patterns as CXCL10 in viral lung infection of pigs [24]. None of these four genes were differentially expressed in IPEC-J2 cells. However, the expression of IL8, coding for the potent neutrophil chemoattractant IL-8, was higher in CELL-FORM relative to CELL-CONTR. Thus, milk formula might induce specific parts of a proinflammatory response in IPEC-J2 cells. Of the genes up-regulated in IPECJ2 cells relative to pig intestinal tissue, MUC1 and DEFB1 stood out as highly differentially expressed, with a relative expression of more than 1000 (data not shown). These genes are coding for proteins secreted by IECs and involved in the first line of defense, and thus expected to be highly expressed in the IPEC-J2 cell line, which consist of IECs only, in contrast to the intestinal tissue consisting of many different cell types.

The IPEC-J2 cell line may, under the conditions used in this study, not be an optimal model to investigate dietrelated effects, since the gene expression differences found in intestinal tissue could not be demonstrated in the IPECJ2 cell line. The expression differences between IPEC-J2 cells and preterm pig intestinal tissue are possibly due to the heterogeneous population of cells in intestinal tissue, in addition to the intestinal microbiota, which may affect the expression level of certain genes. On the other hand, the IPEC-J2 cell line is a homogenous cell population consisting of IECs only. In vivo digestion of the diet may also change its effect on IECs, and exposure to artificially digested diets of the IPEC$\mathrm{J} 2$ cells may provide a situation that more closely resembles that of the intestine. Furthermore, studies could include gene expression analysis of intestinal samples from term born pigs to further determine if the observed differences in gene expression could be due to the difference in maturational state.

\section{Conclusion}

The observed differences in the diet-dependent gene expression patterns between IPEC-J2 cells and intestinal tissue from preterm, newborn pigs underline that responses to environmental stimuli (e.g., diet) may differ markedly between isolated enterocyte cell systems and intact tissue responses, both acting as models for the sensitive newborn intestine. However, this in vitro cell model still provides the opportunity to investigate the interaction between a limited number of factors in a standardized setting, although caution must be exercised in the interpretation of diet-induced effects on gene expression in this model.

\section{Conflict of Interests}

The authors claim to have no conflict of interests in the context of this work.

\section{Acknowledgments}

The authors wish to thank Henriette Vorsholt and Karin Tarp Wendt at Innate Immunology Group, The National Veterinary Institute, Technical University of Denmark, for skilled technical assistance with RNA extraction and qPCR analysis.

\section{References}

[1] R. S. Pitman and R. S. Blumberg, "First line of defense: the role of the intestinal epithelium as an active component of the mucosal immune system," Journal of Gastroenterology, vol. 35, no. 11, pp. 805-814, 2000.

[2] P. Schierack, M. Nordhoff, M. Pollmann et al., "Characterization of a porcine intestinal epithelial cell line for in vitro studies of microbial pathogenesis in swine," Histochemistry and Cell Biology, vol. 125, no. 3, pp. 293-305, 2006.

[3] E. J. A. Veldhuizen, I. Koomen, T. Ultee, A. van Dijk, and H. P. Haagsman, "Salmonella serovar specific upregulation of porcine defensins 1 and 2 in a jejunal epithelial cell line," Veterinary Microbiology, vol. 136, no. 1-2, pp. 69-75, 2009.

[4] V. Mariani, S. Palermo, S. Fiorentini, A. Lanubile, and E. Giuffra, "Gene expression study of two widely used pig intestinal epithelial cell lines: IPEC-J2 and IPI-2I," Veterinary Immunology and Immunopathology, vol. 131, no. 3-4, pp. 278-284, 2009.

[5] T. E. Burkey, K. A. Skjolaas, S. S. Dritz, and J. E. Minton, "Expression of porcine Toll-like receptor 2, 4 and 9 gene transcripts in the presence of lipopolysaccharide and Salmonella enterica serovars Typhimurium and Choleraesuis," Veterinary Immunology and Immunopathology, vol. 130, no. 1-2, pp. 96-101, 2009.

[6] M. M. Geens and T. A. Niewold, "Preliminary characterization of the transcriptional response of the porcine intestinal cell line IPEC-J2 to enterotoxigenic escherichia coli, escherichia coli, and E. coli lipopolysaccharide," Comparative and Functional Genomics, vol. 2010, Article ID 469583, 2010.

[7] L. D. Schmidt, L. J. Kohrt, and D. R. Brown, "Comparison of growth phase on Salmonella enterica serovar Typhimurium invasion in an epithelial cell line (IPEC J2) and mucosal explants from porcine small intestine," Comparative Immunology, Microbiology and Infectious Diseases, vol. 31, no. 1, pp. 63-69, 2008.

[8] A. K. Sonntag, M. Bielaszewska, A. Mellmann et al., "Shiga toxin 2e-producing Escherichia coli isolates from humans and pigs differ in their virulence profiles and interactions with intestinal epithelial cells," Applied and Environmental Microbiology, vol. 71, no. 12, pp. 8855-8863, 2005.

[9] P. W. Lin and B. J. Stoll, "Necrotising enterocolitis," The Lancet, vol. 368, no. 9543, pp. 1271-1283, 2006.

[10] M. A. Quigley, G. Henderson, M. Y. Anthony, and W. McGuire, "Formula milk versus donor breast milk for feeding preterm or low birth weight infants," Cochrane Database of Systematic Reviews, no. 4, Article ID CD002971, 2007. 
[11] C. R. Bjornvad, T. Thymann, N. E. Deutz et al., "Enteral feeding induces diet-dependent mucosal dysfunction, bacterial proliferation, and necrotizing enterocolitis in preterm pigs on parenteral nutrition," American Journal of Physiology, vol. 295, no. 5, pp. G1092-G1103, 2008.

[12] P. T. Sangild, R. H. Siggers, M. Schmidt et al., "Diet- and colonization-dependent intestinal dysfunction predisposes to necrotizing enterocolitis in preterm pigs," Gastroenterology, vol. 130, no. 6, pp. 1776-1792, 2006.

[13] T. Thymann, D. G. Burrin, K. A. Tappenden, C. R. Bjornvad, S. K. Jensen, and P. T. Sangild, "Formula-feeding reduces lactose digestive capacity in neonatal pigs," British Journal of Nutrition, vol. 95, no. 6, pp. 1075-1081, 2006.

[14] E. R. Van Haver, P. T. Sangild, M. Oste, J. L. A. Siggers, A. L. M. Weyns, and C. J. Van Ginneken, "Diet-dependent mucosal colonization and interleukin- $1 \beta$ responses in preterm pigs susceptible to necrotizing enterocolitis," Journal of Pediatric Gastroenterology and Nutrition, vol. 49, no. 1, pp. 90-98, 2009.

[15] R. J. Playford, C. E. Macdonald, and W. S. Johnson, "Colostrum and milk-derived peptide growth factors for the treatment of gastrointestinal disorders," American Journal of Clinical Nutrition, vol. 72, no. 1, pp. 5-14, 2000.

[16] R. H. Siggers, T. Thymann, B. B. Jensen et al., "Elective cesarean delivery affects gut maturation and delays microbial colonization but does not increase necrotizing enterocolitis in preterm pigs," American Journal of Physiology, vol. 294, no. 3, pp. R929R938, 2008.

[17] K. Skovgaard, S. Mortensen, M. Boye, J. Hedegaard, and P. M. H. Heegaard, "Hepatic gene expression changes in pigs experimentally infected with the lung pathogen Actinobacillus pleuropneumoniae as analysed with an innate immunity focused microarray," Innate Immunity, vol. 16, no. 6, pp. 343353, 2010.

[18] M. S. Cilieborg, K. Skovgaard, L. M. Nørgaard, P. T. Sangild, and M. Boye, "Intestinal colonization, gut function and inflammatory responses are moderately influenced by gestational age at birth," in Proceedings of the 14th International Symposium on Microbial Ecology, 2012.

[19] J. Vandesompele, K. De Preter, F. Pattyn et al., "Accurate normalization of real-time quantitative RT-PCR data by geometric averaging of multiple internal control genes," Genome Biology, vol. 3, no. 7, Article ID RESEARCH0034, 2002.

[20] C. L. Andersen, J. L. Jensen, and T. F. Ørntoft, "Normalization of real-time quantitative reverse transcription-PCR data: a modelbased variance estimation approach to identify genes suited for normalization, applied to bladder and colon cancer data sets," Cancer Research, vol. 64, no. 15, pp. 5245-5250, 2004.

[21] H. R. Sargeant, H. M. Miller, and M. A. Shaw, "Inflammatory response of porcine epithelial IPEC J2 cells to enterotoxigenic E. coli infection is modulated by zinc supplementation," Molecular Immunology, vol. 48, pp. 2113-2121, 2011.

[22] R. I. Lehrer, "Primate defensins," Nature Reviews Microbiology, vol. 2, no. 9, pp. 727-738, 2004.

[23] A. M. E. Sidahmed, A. J. León, S. E. Bosinger et al., "CXCL10 contributes to $\mathrm{p} 38$-mediated apoptosis in primary T lymphocytes in vitro," Cytokine, vol. 59, no. 2, pp. 433-441, 2012.

[24] K. Skovgaard, S. Cirera, D. Vasby et al., "Expression of innate immune genes, proteins and microRNAs in lung tissue of pigs infected experimentally with influenza virus (H1N2)," Innate Immunity, 2013. 

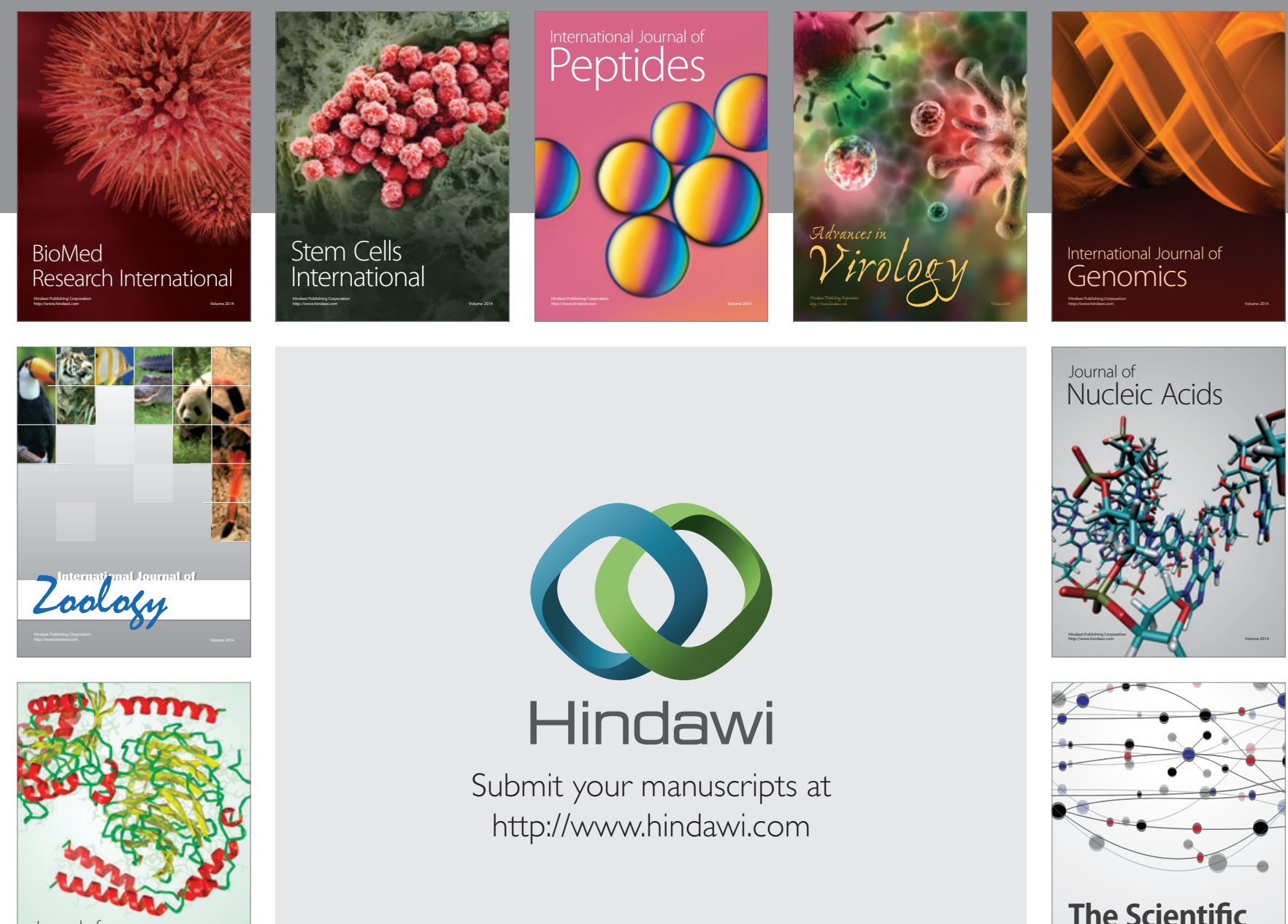

Submit your manuscripts at

http://www.hindawi.com

Journal of
Signal Transduction
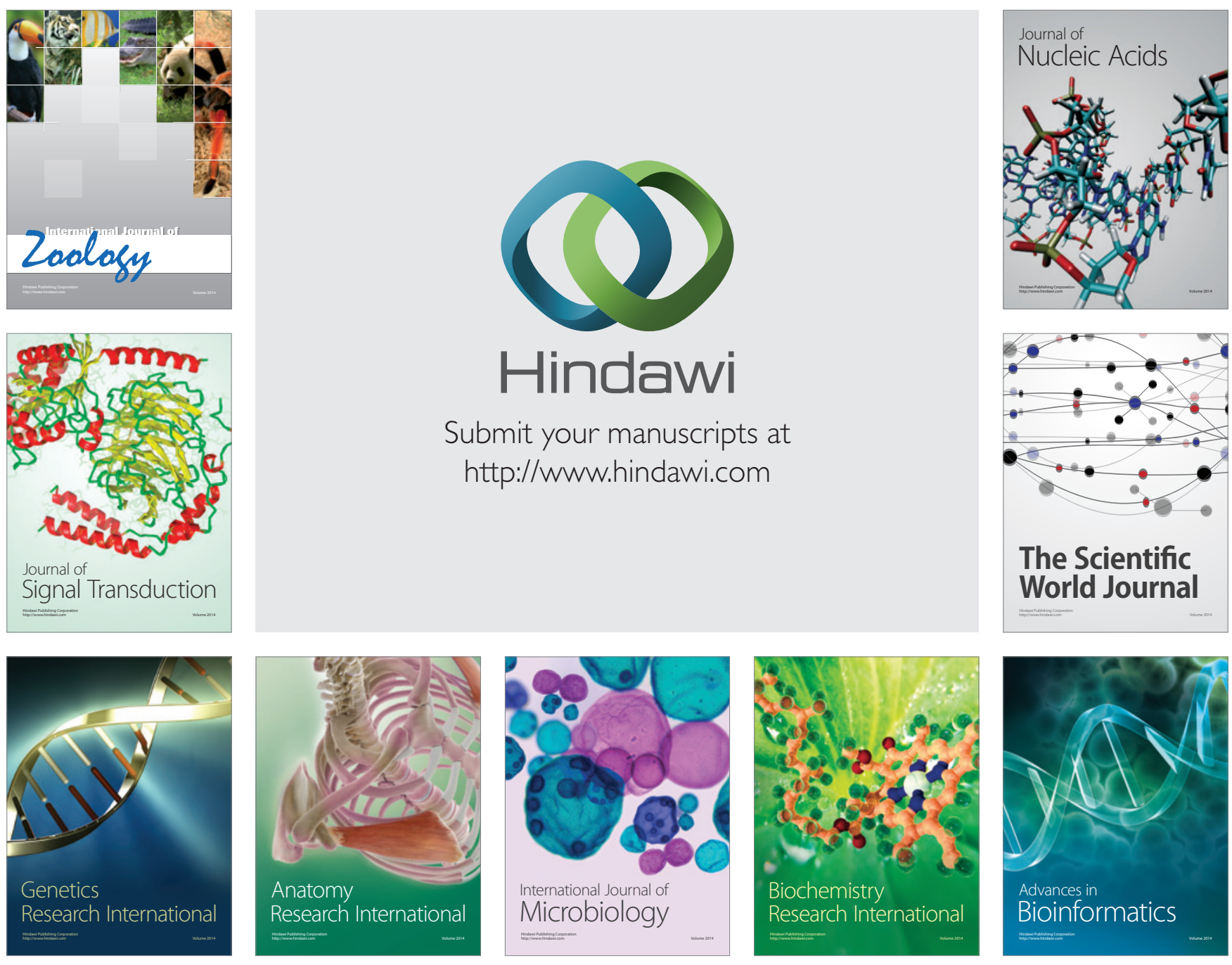

The Scientific World Journal
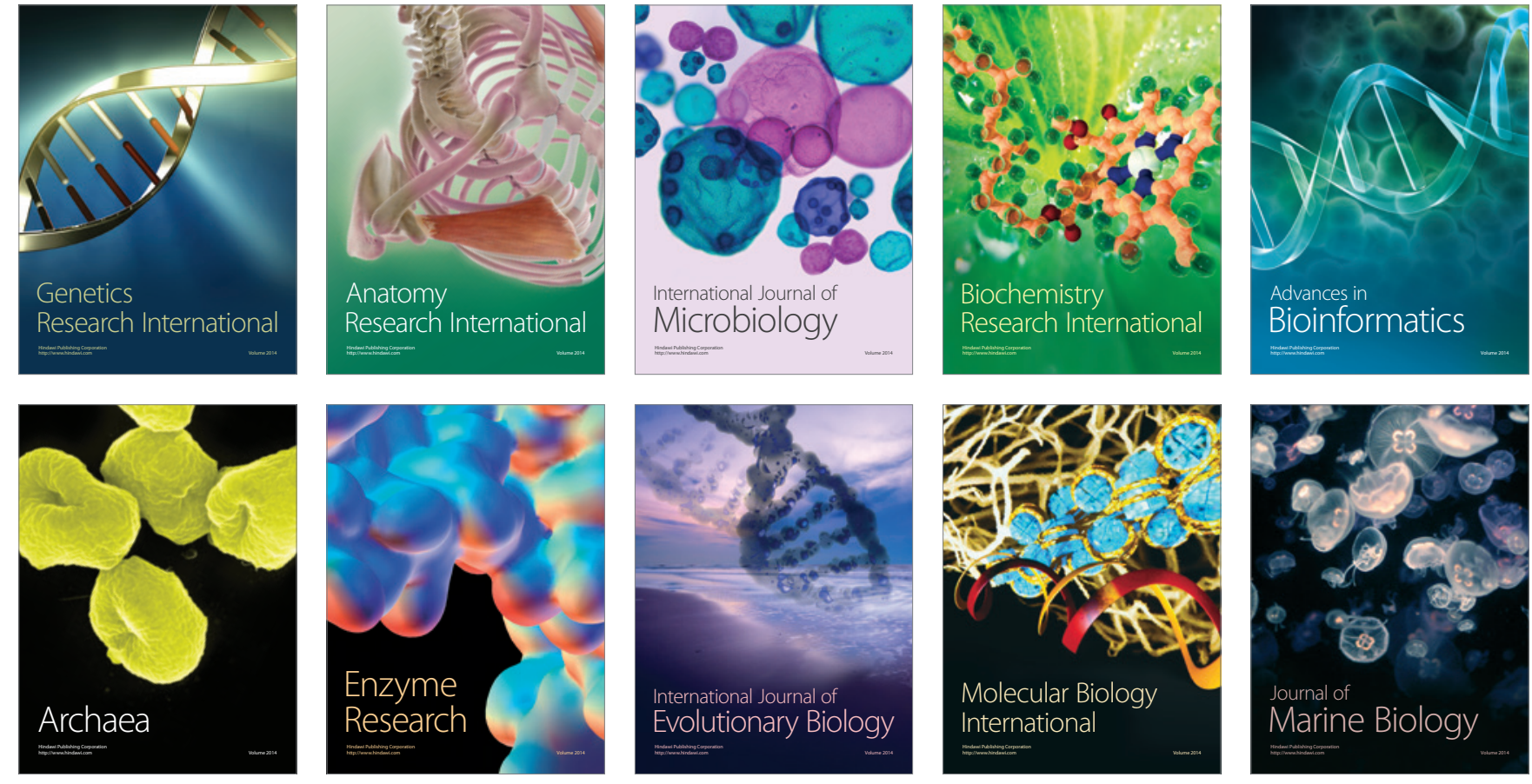